\section{Modified Atmosphere Packaging Reduces Pericarp Browning and Maintains the Quality of 'Huong Chi' Longan Fruit (Dimocarpus Longan) Pretreated with Citric Acid}

\author{
Nguyen Thi Bich Thuy \& Nguyen Thi Hanh
}

Faculty of Food Science and Technology, Vietnam National University of Agriculture, Hanoi 131000, Vietnam

\begin{abstract}
Longan 'Huong Chi' (Dimocarpus longan Lour.) is one of the most favorite and widely exported fruits in Vietnam, but the trading of longan faces considerable challenges due to rapid pericarp browning and decay. Our study aimed to determine the effects of modified atmospheres generated by low-density polyethylene (LDPE), polypropylene bag (PP), and LifeSpan L201 films on the quality and pericarp browning of 'Huong Chi' longan fruit pre-treated with 3.0 $\%$ citric acid and stored at $5^{\circ} \mathrm{C}$. The results showed that LifeSpan L201 and LDPE packaging created an equilibrium atmosphere of $10.66 \pm 0.78 \% \mathrm{O}_{2}, 4.44 \pm 0.64 \% \mathrm{CO}_{2}$, and $15.04 \pm 0.89 \% \mathrm{O}_{2}, 2.96 \pm$ $0.61 \% \mathrm{CO}_{2}$, respectively. The modified atmospheres generated by LifeSpan L201 and LDPE delayed pericarp browning, maintained the total soluble solids (TSS) and vitamin C content, and reduced decay in longan fruit. Meanwhile, the PP packaging resulted in an improperly modified atmosphere which led to severe decay and browning in cold storage conditions.
\end{abstract}

\section{Keywords}

Longan fruit, modified atmosphere packaging, browning

\section{Introduction}

Longan (Dimocarpus longan Lour.) is one of the most abundant and widely exported fruits in Vietnam with several different varieties. Among them, 'Huong Chi' longan fruit is the most popular and favorite one. The trading of longan has been saddled with considerable challenges due to the fruit's very short shelf life, pericarp browning, and decay under ambient conditions (Jiang \& Li, 2001; Tian et al., 2002). Sulfur dioxide $\left(\mathrm{SO}_{2}\right)$ fumigation has been the most widely applied solution in the storage of longan (Chen et al., 2000). However, $\mathrm{SO}_{2}$ fumigation can leave undesirable residues 
which result in a negative effect on the sensory quality of the fruit and pose health risks to consumers (Sivakumar \& Korsten, 2006). The application of $\mathrm{SO}_{2}$ fumigation has been restricted or prohibited in many countries (Khan et al., 2017). Previous studies have been carried out to investigate alternatives such as chitosan coating (Jiang \& Li, 2001; Apai et al., 2009), hydrochloric acid (Apai, 2010), hydroxyl radical application (Duan et al., 2011), chlorine dioxide fumigation (Saengnil et al., 2014; Chumyam et al., 2017), and adenosine triphosphate treatment (Chen et al., 2015) to prolong the shelf life and prevent pericarp browning for longan fruit.

In postharvest management, packaging plays an important role not only in reducing the transpiration rate of fresh produce and preventing microbial contamination, but also in building an appropriate relationship between the respiration intensity of fresh produce and the gas movement via the packaging. The modified atmosphere is created to maintain proper respiration and prolong the shelf life of fruits and vegetables. This is referred to as modified atmosphere packaging (MAP) technology. The effect of MAP depends on the equilibrium atmosphere achieved within a package given the commodity mass and respiration intensity, and the film permeability to $\mathrm{O}_{2}$ and $\mathrm{CO}_{2}$ (Kader et al., 1989). MAP has been applied to alleviate greyish peel browning in banana (Nguyen et al., 2004), and core browning in 'Yali' pear (Cheng et al., 2015) via inhibiting the effects of polyphenol oxidase (PPO) and phenylalanine ammonialyase (PAL). The modified atmosphere with $17.0 \% \quad \mathrm{O}_{2}$ and $6.0 \% \mathrm{CO}_{2}$ reduced the transpiration rate, prevented weight loss, and maintained the color and sensory qualities of litchi during long-term storage (Sivakumar \& Bautista-Baños, 2014). In longan, Khan et al. (2016) investigated the effects of MAP created by different films and found that polyethylene (PE) packaging effectively prolonged the shelf life and delayed fruit pericarp browning. In addition, Chamnan et al. (2019) reported that PE packaging yielded a longer shelf life for longan fruit. Although MAP provides many advantages, the creation of an improper modified atmosphere can increase anaerobic respiration, which leads to high $\mathrm{CO}_{2}$ and ethanol contents, resulting in off-flavors and decay development (Pesis et al., 2002). PE film with a thickness of $80 \mu \mathrm{m}$ and without perforation caused off-flavor for longan fruit due to fermentation (Khan et al., 2016).

Citric acid has been known as an antibrowning agent, and inhibits the activity of PPO by reducing $\mathrm{pH}$ and binding $\mathrm{Cu}^{2+}$ in the active sites of PPO to form an inactive complex. Dipping fruits in citric acid has yielded satisfactory results for longan and lichi. However, high concentrations of citric acid can cause injuries on the fruit surface, which could be reduced by the protection of the coating layer (Apai et al., 2009). Therefore, the objective of our study was to evaluate the effects of packaging films on modifying the package atmosphere to maintain overall quality and reduce pericarp browning in citric acid treated 'Huong Chi' longan fruit in cold conditions.

\section{Materials and Methods}

\section{Materials}

\section{Longan fruits}

Longan fruits ('Huong Chi' cultivar) at the commercial maturity stage were harvested from an orchard in Hong Nam district, Hung Yen province in Vietnam. Harvested longan fruits were shortly transported to the postharvest laboratory at the Vietnam National University of Agriculture. The selected fruits for the experiments were devoid of injury and disease.

\section{Packaging films}

Three types of MAP bags with a size of $30 \mathrm{x}$ $35 \mathrm{~cm}$ were tested: commercially available LifeSpan ${ }^{\circledR}$ L201 (Amcor, Victoria, Australia); commercial low-density polyethylene (LDPE) bags; and commercial polypropylene (PP) bags, and the thicknesses of these film bags were 20, 70 , and $35 \mu \mathrm{m}$, respectively. The LDPE bags had $0.01 \%$ of the bag area perforated with perforations of $1 \mathrm{~mm}$ in diameter. The PP bags were perforated with 35 micro-perforations by a needle $0.5 \mathrm{~mm}$ in diameter.

\section{Treatments}


The selected longan fruits were washed with clean water and sanitized using 150ppm sodium hypochlorite for $3 \mathrm{~min}$, and then drained. After that, the fruits were immersed in $3 \%$ citric acid for $5 \mathrm{~min}$ (selected based on our preliminary experiment, in which longan fruit was immersed in $1.0 \%, 3.0 \%$, or $5.0 \%$ citric acid for $5 \mathrm{~min}$ ), and then air-dried at room temperature. A bunch of longan fruits (500 grams) was packed in one of the three different types of bags. There were 15 bags of 3 replicates for each type. The fruits treated with citric acid and then put in net bags were considered as the control. All the packed longan fruits were then stored at $5 \pm 1^{\circ} \mathrm{C}$ for 4 weeks. Sampling was performed weekly for quality assessment.

\section{Analytical methods}

In-package gas concentration: The $\mathrm{O}_{2}$ and $\mathrm{CO}_{2}$ concentrations of the free volume inside the packages were measured using a dual gas analyzer ICA250 (International Control Analyzer Ltd.).

Weight loss: Weight loss was calculated by the equation $(\mathrm{A}-\mathrm{B}) * 100 / \mathrm{A}$, where, $\mathrm{A}$ is the initial weight of a sample (day 0) and B is the weight of that sample after the storage period.

Color: The color of the longan fruit was measured by a colorimeter (Minolta, model CR400, Japan) and expressed by the L-value (0-100) mean of 10 fruits per replicate for each treatment. The measurement was performed at 3 points on the surface of each fruit.

Pericarp browning: Pericarp browning of the longan fruit was evaluated according to the method of Jiang \& Li (2001), and based upon the browned areas on the fruit surface following the scale: $1=$ no browning; $2=$ slight browning; $3=$ $<25 \%$ surface browning; $4=25-50 \%$ surface browning; and $5=>50 \%$ surface browning.

Total soluble solids: An Atago PAL 1 digital refractometer (Atago Co Ltd.) was used to determine the total soluble solids (TSS) of the flesh juice. The TSS content was expressed as \% Brix (\% Bx).

Titratable acidity (TA): The total acid content of the fruit juice was determined by the titration method with a $0.1 \mathrm{~N} \mathrm{NaOH}$ solution in the presence of $1 \%$ phenolphthalein. The results were expressed as percentages $(\mathrm{w} / \mathrm{w})$ of malic acid.

Vitamin $C$ content: Vitamin $\mathrm{C}$ was determined with the specific titrant 2,6Dichlorophenolindophenol (DCPIP) according to AOAC 967.21. Two (2) grams of a sample was weighed exactly into a breaker. Forty (40) $\mathrm{mL}$ of oxalic acid was added and stirred for $5 \mathrm{~min}$, then filtrated into a $100-\mathrm{mL}$ volumetric flask and diluted to volume with distilled water. Ten (10) $\mathrm{mL}$ was pipetted into a small flask and $2.5 \mathrm{~mL}$ acetone was added. The solution was titrated with DCPIP until a faint pink color persisted for 15 seconds. The following formula was used to calculate the concentration of vitamin $\mathrm{C}$ :

$$
\text { Vitamin } \mathrm{C}(\mathrm{mg} / 100 \mathrm{~g})=\frac{(a-b) \times f \times V 1 \times 100}{W \times V 2}
$$

whereas $\mathrm{a}$ is the $\mathrm{mL}$ of the test solution titration, $\mathrm{b}$ is the $\mathrm{mL}$ of the blank test titration, $\mathrm{f}$ is the $\mathrm{mg}$ ascorbic acid equivalent to one $\mathrm{mL}$ DPIP standard solution, V1 is the volume of the initial test solution, V2 is the volume of the test solution titrated, and $\mathrm{W}$ is the weight of the sample.

Rate of fruit decay: The fruits were visually observed for fungal spoilage and fruit rots. The number of decayed fruits was recorded and the fruit decay percentage was calculated as follows:

$\%$ Fruit decay $=\frac{A}{B} \times 100$

where $\mathrm{A}$ is the number of decayed fruits and $\mathrm{B}$ is the total number of fruits in the sample. The rate of decay was expressed as the arcsine of the square root of the fruit decay percentage.

Statistical analysis: Analysis of variance (ANOVA) was performed and Duncan's multiple range tests were used to compare sample means at each time of assessment.

\section{Results}

\section{In-package gas concentration}

The $\mathrm{CO}_{2}$ and $\mathrm{O}_{2}$ concentrations inside the packages are shown in Figure 1. In all the treatments, the $\mathrm{CO}_{2}$ level increased while the $\mathrm{O}_{2}$ 
concentration was reduced inside the packaging films. The concentration of $\mathrm{O}_{2}$ and $\mathrm{CO}_{2}$ in the modified atmosphere created by the LifeSpan bag (Figure 1C) reached equilibrium at $10.66 \pm$ $0.78 \% \mathrm{O}_{2}$ and $4.44 \pm 0.64 \% \mathrm{CO}_{2}$ after 7 days of storage at $5^{\circ} \mathrm{C}$. The gas concentration inside the LDPE packages (Figure 1A) at equilibrium atmosphere contained a higher $\mathrm{O}_{2}$ concentration $(15.04 \pm 0.89)$ and a lower $\mathrm{CO}_{2}$ level $(2.96 \pm$ $0.61)$ than that in the LifeSpan packages. The $\mathrm{CO}_{2}$ concentration in the PP bags (Figure 1B) increased progressively to higher than $15 \%$, while the $\mathrm{O}_{2}$ concentration reduced to lower than $5 \%$ after 28 days of storage.

\section{Weight loss}

As shown in Figure 2, weight loss of the longan fruit increased progressively during storage in the non-packaged sample and all the packaged samples. However, an extremely significant higher weight loss was observed in the control sample compared to the packaged samples in the modified atmosphere. There were no significant differences $(P<0.05)$ among the three types of films used as MAP in their effect on reducing weight loss of longan fruit.

\section{Color (L-value) and pericarp browning}

Figures $\mathbf{3 A}$ and $\mathbf{3 B}$ show the effects of the MAP on maintaining skin color as well as reducing pericarp browning of longan fruit. The L-value of the skin declined gradually during storage in all the treatments (Figure 3A). However, the L-value was significantly lower in the non-packaged longan fruit compared to all the packaged fruits after 21 days of storage. This was extremely obvious after 28 days of storage.At the end of the storage, the L-values were significantly higher in longan fruits packaged in the LDPE and LifeSpan films than in the fruits packaged in the PP film.
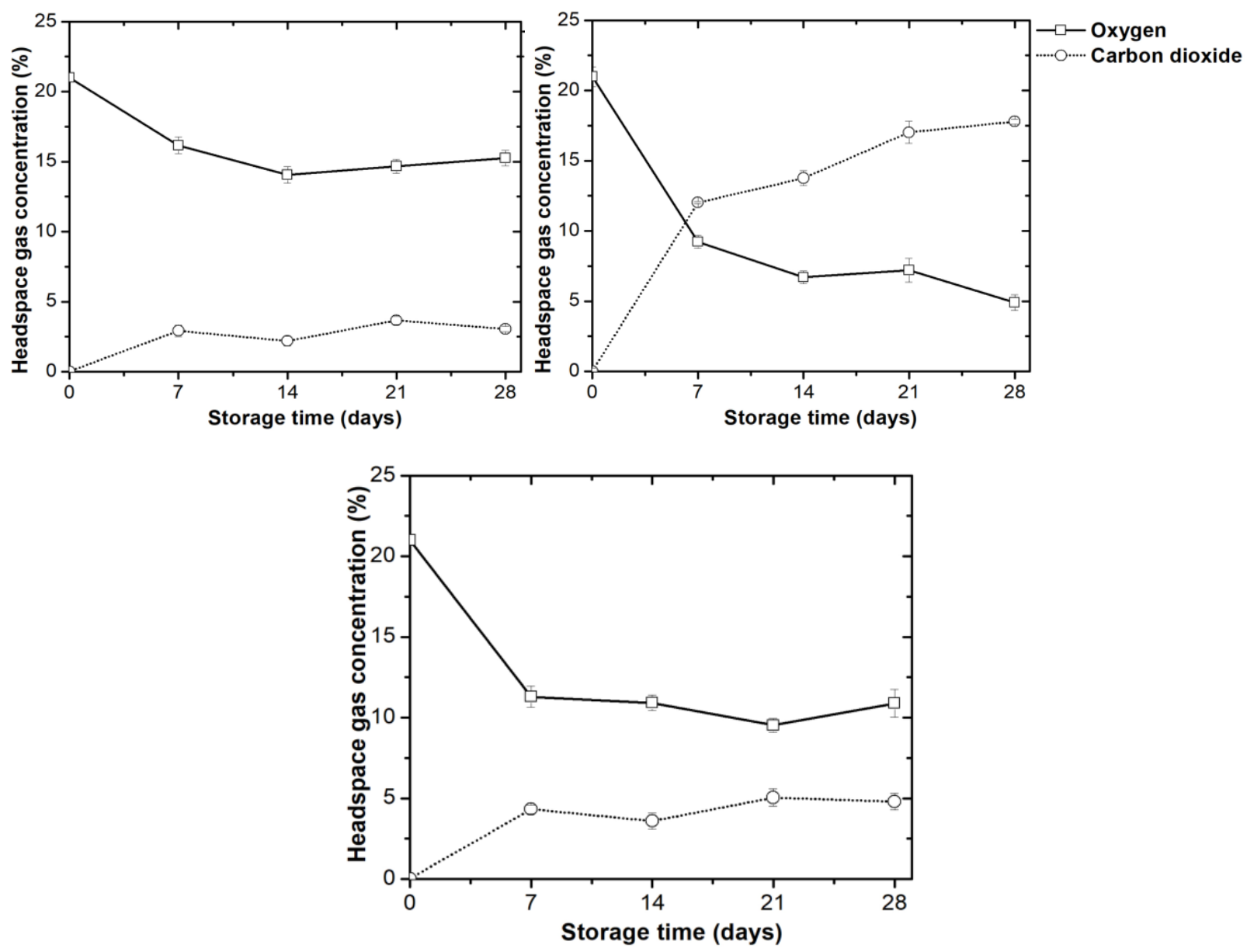
Figure 1. Oxygen and carbon dioxide concentrations (\%) in LDPE (A), PP (B), and LifeSpan (C) packages of longan fruits stored at $5^{\circ} \mathrm{C}$. Vertical bars represent mean \pm standard error.

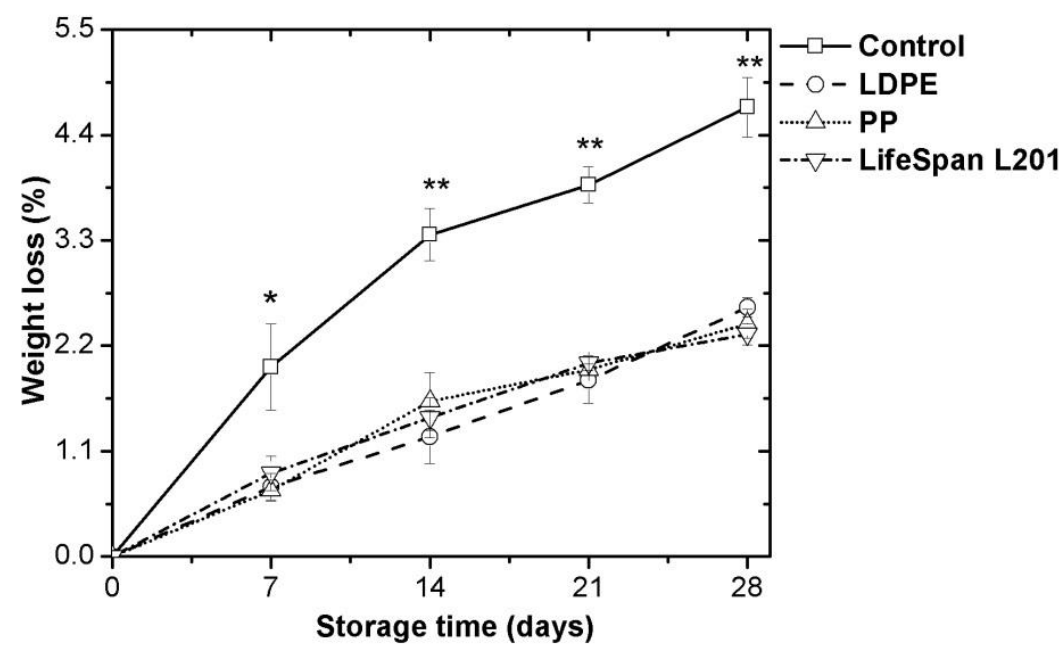

Figure 2. Weight loss of the non-packaged longan fruit and longan fruit packaged in LDPE, PP, and LifeSpan bags. Vertical bars represent mean \pm standard error.
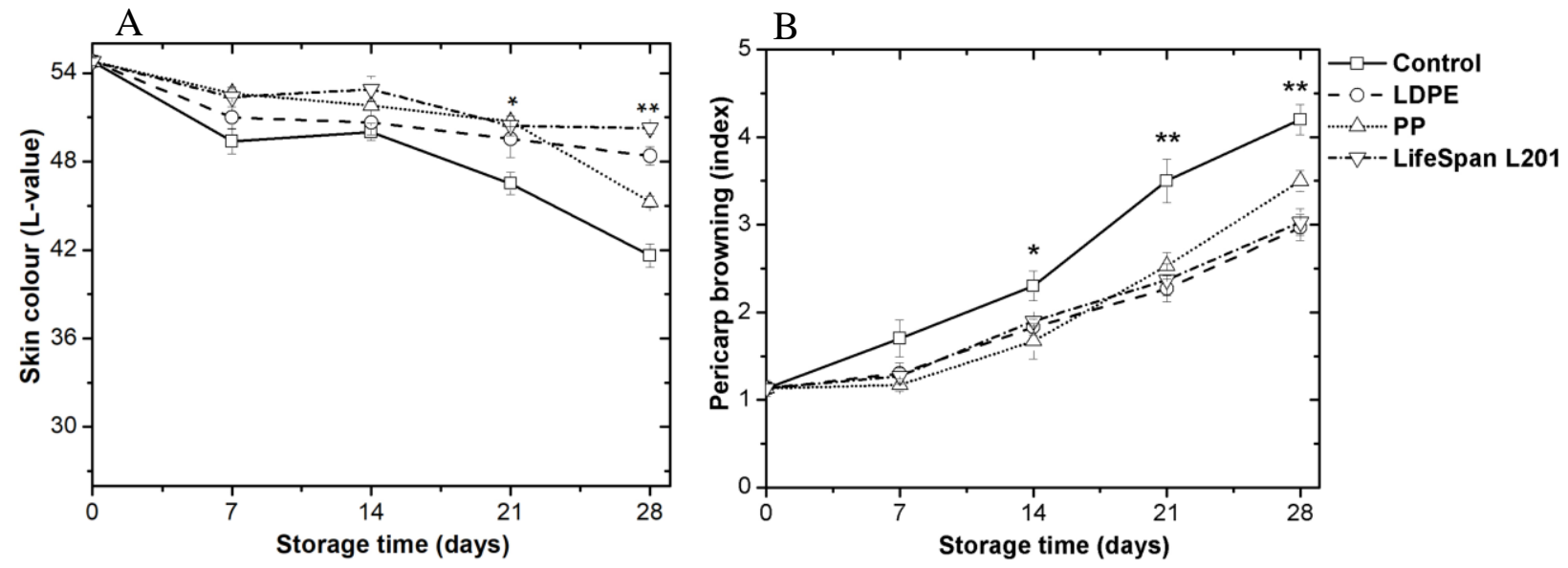

Figure 3. Skin color (A) and pericarp browning (B) of non-packaged longan fruit and longan fruit packaged in LDPE, PP, and LifeSpan bags. Vertical bars represent mean \pm standard error.

In agreement with the L-value results, the pericarp browning index of the longan fruit increased dramatically during storage. The pericarp browning index level of the longan fruit in the control was significantly higher compared to all the MAP after 14 days of storage (Figure 3B). There were no marked differences in the browning level among the longan fruit packaged in the different bags until after 21 days of storage. However, after 28 days of storage, the pericarp browning index of the PP packaged longan fruit was significantly higher than the others $(P<0.05)$.

\section{Total soluble solids and titratable acidity}

The effects of the MAP on the TSS and TA of the longan fruit are shown in Figures $4 \mathrm{~A}$ and 4B. As indicated in Figure 4A, the TSS of the longan fruit in all the treatments reduced slightly during storage. No considerable differences in the TSS of the longan fruit were observed among the treatments during the first 14 days of storage. However, in the last two weeks of storage, the TSS of the non-packaged longan fruits was significantly lower than the other packaged fruits $(P<0.05)$. After 28 days of storage, the LifeSpan and LDPE packaging films maintained a higher 
TSS level in the pulp of the longan fruit than the PP film $(P<0.05)$. The same decreasing trend was observed in the TA of the longan fruit during storage. However, the MAP did not considerably lower the reduction of TA in the longan fruit (Figure 4B).

\section{Vitamin C content}

Figure 5 shows the effect of the MAP on the change of vitamin $\mathrm{C}$ content in the longan fruit. The vitamin $\mathrm{C}$ content in the longan fruit gradually decreased during storage among the treatments from $138.40 \mathrm{mg} / 100 \mathrm{~g}$ on the initial day to $98.83,107.67,95.07$, and $111.85 \mathrm{mg} / 100 \mathrm{~g}$, respectively in the control treatment, and the LDPE, PP, and LifeSpan L201 packaging, after 28 days of storage. There were no significant differences in vitamin $\mathrm{C}$ content observed among the treatments until day 21 of storage. However, on the $28^{\text {th }}$ day of storage, the vitamin $\mathrm{C}$ content in the non-packaged longan fruit and the fruit packaged with PP bags were remarkably lower than that in the longan fruit packaged with LifeSpan $201(P<0.05)$. In addition, the LDPE bag maintained a noticeably higher vitamin $C$ level in the longan fruit than the PP bag, which had a level that was comparable to the control.

\section{Rate of fruit decay}

There was no observed fruit decay after 7 days of storage (Figure 6). However, the fruit decay percentage increased markedly after 14 days of storage in all the treatments. After 28 days of storage, the recorded percentage of fruit
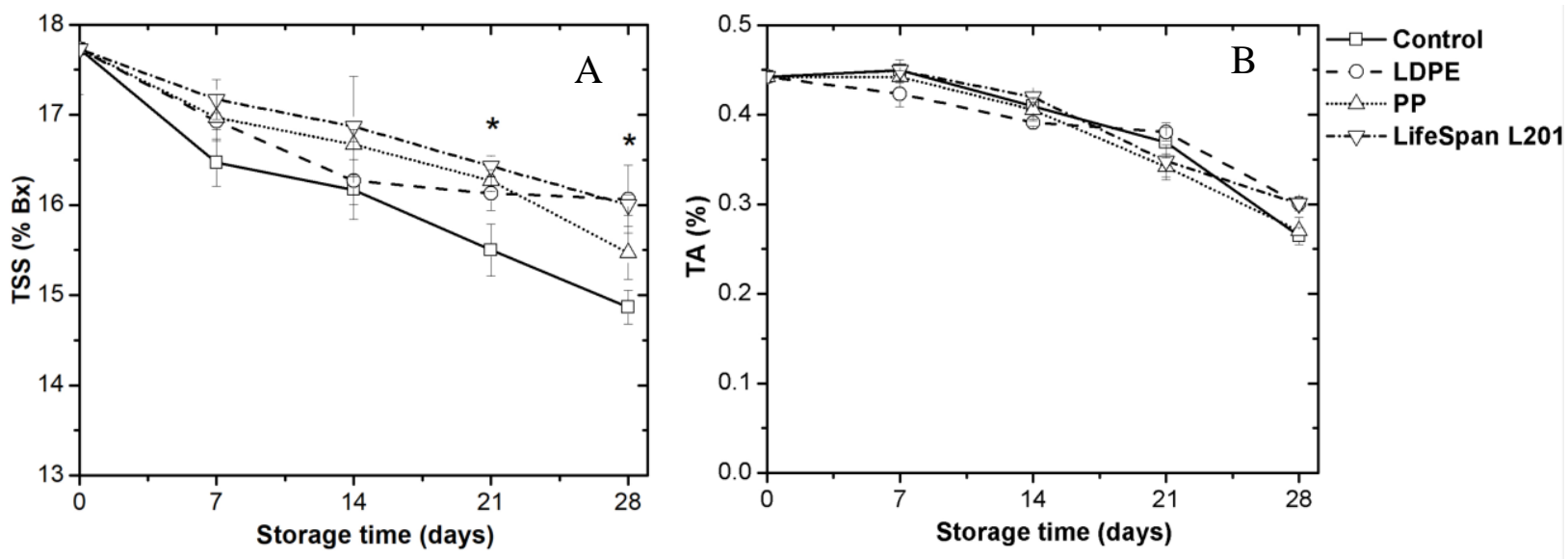

Figure 4. TSS content (A) and TA content $(B)$ of non-packaged longan fruit and longan fruit packaged in LDPE, PP, and LifeSpan bags. Vertical bars represent mean \pm standard error.

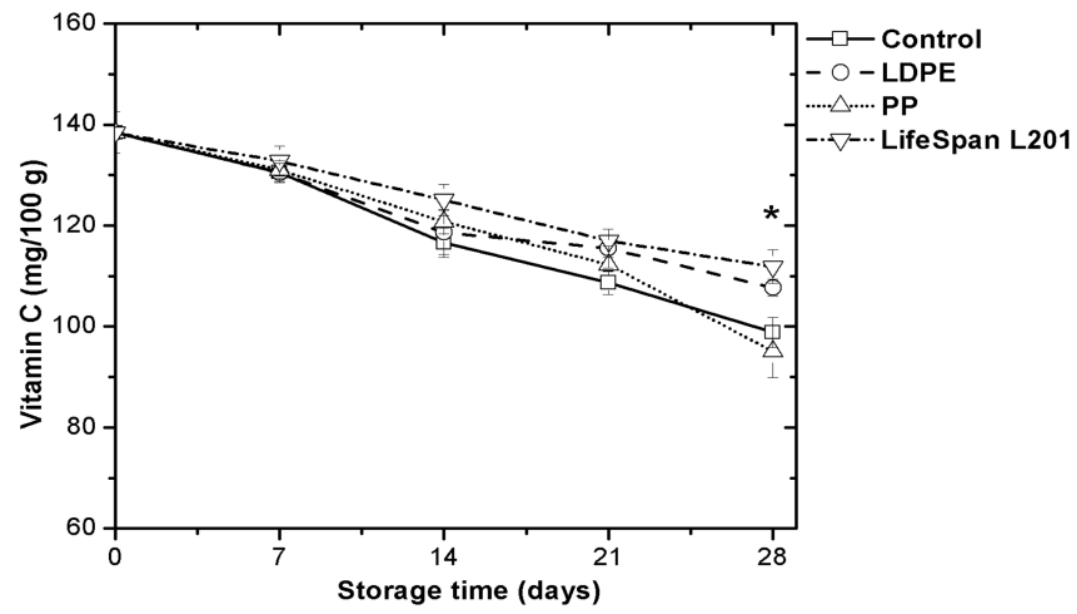

Figure 5. Vitamin C in non-packaged longan fruit and longan fruit packaged in LDPE, PP, and LifeSpan bags. Vertical bars represent mean \pm standard error. 


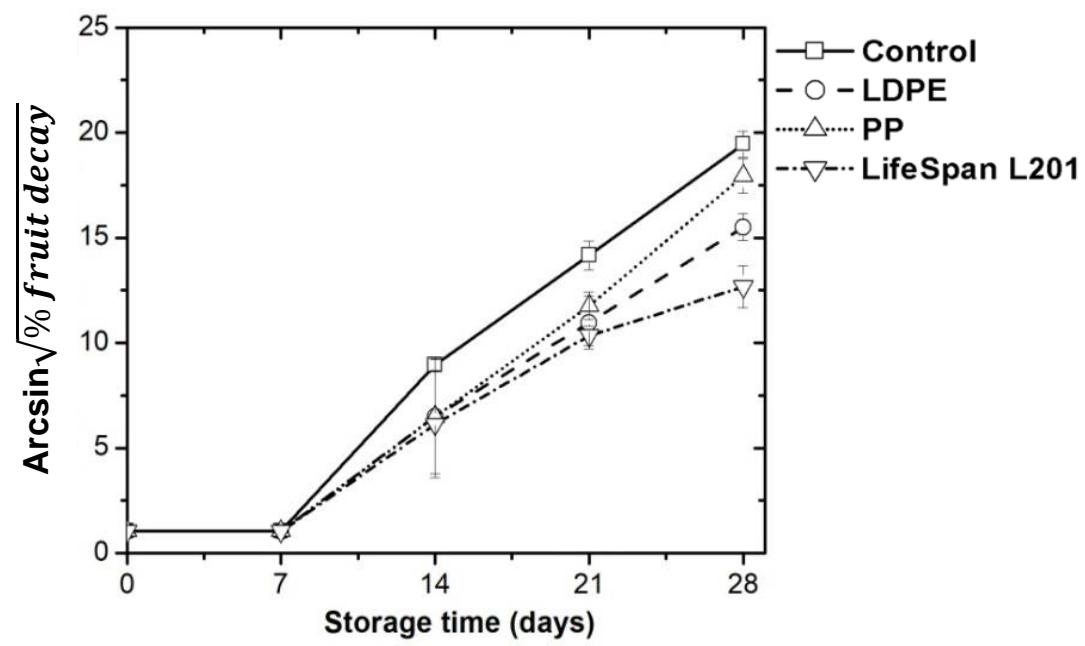

Figure 6. Rate of decay of non-packaged longan fruit and longan fruit packaged in LDPE, PP, and LifeSpan bags. Vertical bars represent mean \pm standard error.

decay in the control was $11.12 \%$ (19.46 arcsin square root of fruit decay percentage), while the percentages were $7.16 \%$ and $4.86 \%$ (15.50 and 12.67 arcsin square root of fruit decay percentage) in the LDPE and LifeSpan packaging treatments, respectively. The LDPE and LifeSpan modified atmosphere packaging significantly reduced the decay of the longan fruit. However, the PP packaging film did not show a significant effect on this attribute during storage $(P<0.05)$.

\section{Discussion}

The concentration of gases, especially $\mathrm{O}_{2}$, $\mathrm{CO}_{2}$, and $\mathrm{C}_{2} \mathrm{H}_{4}$, in the storage atmosphere is one of the major factors that affects the quality and postharvest life of fresh fruits and vegetables. A modified atmosphere containing a low level of $\mathrm{O}_{2}$ or high concentration of $\mathrm{CO}_{2}$ can retard fruit ripening, delay senescence, and maintain the quality of fresh produce (Kader et al., 1989). In our study, the LifeSpan and LDPE packaging films created equilibrium modified atmospheres (EMA) after 1 week and 2 weeks, respectively, while the PP packaging film could not create an EMA. Wang \& Sugar (2013) also showed that commercial LifeSpan MAP bags could generate an equilibrium atmosphere of $12.3 \% \mathrm{O}_{2}+5.6 \%$ $\mathrm{CO}_{2}$ after 2 weeks of 'Bartlett' pears storage. In addition, a PE bag with a thickness of $80 \mu \mathrm{m}$ used for longan storage developed the equilibrium atmosphere of $4 \% \mathrm{O}_{2}+9 \% \mathrm{CO}_{2}$ (Khan et al., 2016). Furthermore, previous studies reported that gas equilibrium could be created by perforation-mediated MAP. Hussein et al. (2015) found that PE film with 3,6 , or 9 perforations, $0.8 \mathrm{~mm}$ in diameter, reduced the $\mathrm{O}_{2}$ concentration to $17.6 \mathrm{kPa}, 18.6 \mathrm{kPa}$, and $18.4 \mathrm{kPa}$, respectively, within packages of pomegranate aril. The $\mathrm{CO}_{2}$ concentration within the packages also increased. LDPE film packaging $(22.0 \times$ $30.0 \mathrm{~cm}$ ) with 8 perforations $0.5 \mathrm{~mm}$ in diameter used for tomato storage also created an EMA with a lower $\mathrm{O}_{2}$ and higher $\mathrm{CO}_{2}$ concentration compared to the air ( $\mathrm{Li}$ et al., 2010). In the present study, LDPE bags with perforations of $0.01 \%$ of the surface area resulted in a higher level of $\mathrm{O}_{2}$ and a lower level of $\mathrm{CO}_{2}$ inside the packages. The gas composition obtained by the LifeSpan and LDPE provided substantial benefits to the longan fruit.

Although all the packaging films maintained the L-value and delayed the pericarp browning of the longan fruit, the LifeSpan and LDPE films showed the strongest effects at the later stages of storage. The browning reaction has been shown to be accelerated by polyphenol oxidase (PPO) and peroxidase (POD), which are two enzymes 
that convert phenolic compounds to $o$-quinones, and phenylalanine ammonia lyase (PAL), which catalyzes the biosynthesis of phenolic compounds (Nguyen et al., 2004; Khan et al., 2016). In agreement with our study, a modified atmosphere with $12 \%$ oxygen and $4 \% \mathrm{CO}_{2}$ inhibited PPO and PAL activities resulting in less peel browning in banana (Nguyen et al., 2004). The modified atmosphere of $17 \% \quad \mathrm{O}_{2}$ and $6 \%$ $\mathrm{CO}_{2}$ created by perforated PP packaging was also reported to reduce pericarp browning in litchi (Sivakumar \& Korsten, 2006). The results in our study suggested that the effects of the LifeSpan and LDPE films on reducing pericarp browning in longan fruit may involve the inhibition of enzyme activities. Moreover, pericarp browning in longan fruit has also been shown to be associated with desiccation (Jiang et al., 2002), which rapidly occurs after harvest. In the present study, all the packages significantly reduced the desiccation of the longan fruit, which was reflected in weight loss reduction. Hence, the pericarp browning of packaged fruits was inhibited as a consequence. In addition, it was observed that the L-value was maintained in the non-packaged fruit during the first 2 weeks of storage, which may support the effects of the citric acid treatment as an anti-browning agent.

Even though, longan fruit is a nonclimacteric fruit, the TSS and TA were shown to decrease gradually after harvest, even in cold storage conditions (Jiang et al., 2002). All packaging films in our study reduced the loss of the TSS in longan fruit, but the LDPE and LifeSpan films showed higher effects than the PP after 28 days of storage. The effect of the MAP on the TSS was probably due to the low concentration of $\mathrm{O}_{2}$ and high level of $\mathrm{CO}_{2}$ atmosphere which reduced respiratory metabolism, resulting in decreased consumption of the TSS as substrates. At the end of storage, the loss of the TSS content in the longan fruit packaged in PP bags was more rapid. This could have been caused by anaerobic respiration occurring inside the PP bags due to undesirable atmosphere conditions with too low $\mathrm{O}_{2}$ and high $\mathrm{CO}_{2}$ concentrations. In agreement with our results, Khan et al. (2016) found that PE films maintained the TSS and TA contents in longan fruits, while the PP film led to a higher reduction of the TSS and TA. On the other hand, the MAP created by the LDPE and LifeSpan L201 films provided a preserving effect on vitamin $\mathrm{C}$ content in longan fruit, which was not obtained by the PP film. The present study agrees with Wang \& Sugar (2013), who reported that commercial LifeSpan L254 suppressed the loss of ascorbic acid during storage via reducing membrane leakage. Modified atmosphere packaging and a controlled atmosphere were determined to decrease oxidative stress through the retention of ascorbic acid in fruits and vegetables (Hodges et al., 2004).

The optimum gas composition in the storage atmosphere can suppress fungal decay of fruit, but the undesired modified atmosphere created by PP packaging film may cause physiological disorders, which could be followed by disease symptoms (Khan et al., 2016). In our study, the PP packaging film could not decrease the fruit decay compared to the control, which is the extent of the above discussion. Meanwhile, the LDPE and LifeSpan films strongly reduced the decay of the longan fruit after 4 weeks of storage. These results were in agreement with the studies on litchi and sweet cherry that reported that the appropriate MAP can reduce fruit decay, which was related to the inhibitory effect on the growth of disease pathogens (Sivakumar \& Korsten, 2006; Wang et al., 2015).

\section{Conclusions}

The LDPE and LifeSpan packaging films not only prevented the desiccation but also created the optimum EMA for the storage of longan fruit. This EMA significantly reduced pericarp browning, maintained the TSS content, reduced the loss of vitamin $\mathrm{C}$, which contributes to the edible quality of fruit, and minimized fruit decay during cold storage. The PP packaging produced an undesired modified atmosphere for longan fruit, which resulted in severe decay symptoms and browning at the end of storage. Fruit stored in LifeSpan packaging films had the longest shelf life of 28 days, with a browning index less than 3 , and a percentage of fruit decay 
less than 5\%. This MAP extended the shelf life of the longan fruit more than 7 days longer than the control.

\section{Acknowledgments}

This study was funded by the "Development of innovative technologies on postharvest management for longan fruit fulfilling the requirement of domestic trading and exporting" project, No. 739/HD-BNN-KHCN, Ministry of Agriculture and Rural Development, Vietnam.

\section{References}

Apai W. (2010). Effects of fruit dipping in hydrochloric acid then rinsing in water on fruit decay and browning of longan fruit. Crop Protection. 29(10): 1184-1189.

Apai W., Sardsud V., Boonprasom P. \& Sardsud U. (2009). Effects of chitosan and citric acid on pericarp browning and polyphenol oxidase activity of longan fruit. Songklanakarin Journal of Science \& Technology. 31(6): 621-628.

Chamnan S., Varith J., Jaturonglumlert S., Klinkajorn P. \& Phimphimol J. (2019). The effect of packaging materials on the quality of freshness of longan fumigated with medium concentration-ozone gas. Pertanika Journal of Science and Technology. 27: 159168.

Chen M., Lin H., Zhang S., Lin Y., Chen Y. \& Lin Y. (2015). Effects of adenosine triphosphate (ATP) treatment on postharvest physiology, quality and storage behavior of longan fruit. Food and Bioprocess Technology. 8(5): 971-982.

Chen S., Chen J., Hong Q. \& Lin H. (2000). Current situation and advances in post-harvest storage and transportation technologies of longan fruit. I International Symposium on Litchi and Longan 558. 343-351.

Cheng Y., Liu L., Zhao G., Shen C., Yan H., Guan J. \& Yang K. (2015). The effects of modified atmosphere packaging on core browning and the expression patterns of PPO and PAL genes in 'Yali'pears during cold storage. LWT-Food Science and Technology. 60(2): 1243-1248.

Chumyam A., Shank L., Faiyue B., Uthaibutra J. \& Saengnil K. (2017). Effects of chlorine dioxide fumigation on redox balancing potential of antioxidative ascorbate-glutathione cycle in 'Daw' longan fruit during storage. Scientia Horticulturae. 222: 76-83.

Duan X., Zhang H., Zhang D., Sheng J., Lin H. \& Jiang Y. (2011). Role of hydroxyl radical in modification of cell wall polysaccharides and aril breakdown during senescence of harvested longan fruit. Food Chemistry.
128(1): 203-207.

Hodges D. M., Lester G. E., Munro K. D. \& Toivonen P. M. (2004). Oxidative stress: importance for postharvest quality. HortScience. 39(5): 924-929.

Hussein Z., Caleb O. J., Jacobs K., Manley M. \& Opara U. L. (2015). Effect of perforation-mediated modified atmosphere packaging and storage duration on physicochemical properties and microbial quality of fresh minimally processed 'Acco'pomegranate arils. LWT-Food Science and Technology. 64(2): 911-918.

Jiang Y. \& Li Y. (2001). Effects of chitosan coating on postharvest life and quality of longan fruit. Food Chemistry. 73(2): 139-143.

Jiang Y., Zhang Z., Joyce D. C. \& Ketsa S. (2002). Postharvest biology and handling of longan fruit (Dimocarpus longan Lour.). Postharvest Biology and Technology. 26(3): 241-252.

Kader A. A., Zagory D., Kerbel E. L. \& Wang C. Y. (1989). Modified atmosphere packaging of fruits and vegetables. Critical Reviews in Food Science and Nutrition. 28(1): 1-30.

Khan M. R., Sripethdee C., Chinsirikul W., Sane A. \& Chonhenchob V. (2016). Effects of film permeability on reducing pericarp browning, preventing postharvest decay and extending shelf life of modified atmosphereretail packaged longan fruits. International Journal of Food Science and Technology. 51(8): 1925-1931.

Khan M. R., Suwanamornlert P., Leelaphiwat P., Chinsirikul W. \& Chonhenchob V. (2017). Quality and biochemical changes of longan (Dimocarpus longan Lour cv. Daw) fruit under different controlled atmosphere conditions. International Journal of Food Science and Technology. 52(10): 2163-2170.

Li L., Li X.-H. \& Ban Z.-J. (2010). A mathematical model of the modified atmosphere packaging (MAP) system for the gas transmission rate of fruit produce. Food Technology and Biotechnology. 48(1): 71-78.

Nguyen T. B. T., Ketsa S. \& van Doorn W. G. (2004). Effect of modified atmosphere packaging on chillinginduced peel browning in banana. Postharvest Biology and Technology. 31(3): 313-317.

Pesis E., Dvir O., Feygenberg O., Arie R. B., Ackerman M. \& Lichter A. (2002). Production of acetaldehyde and ethanol during maturation and modified atmosphere storage of litchi fruit. Postharvest Biology and Technology. 26(2): 157-165.

Saengnil K., Chumyam A., Faiyue B. \& Uthaibutra J. (2014). Use of chlorine dioxide fumigation to alleviate enzymatic browning of harvested 'Daw' longan pericarp during storage under ambient conditions. Postharvest Biology and Technology. 91: 49-56.

Sivakumar D. \& Bautista-Baños S. (2014). A review on the use of essential oils for postharvest decay control and maintenance of fruit quality during storage. Crop Protection. 64: 27-37. 
Sivakumar D. \& Korsten L. (2006). Influence of modified atmosphere packaging and postharvest treatments on quality retention of litchi cv. Mauritius. Postharvest Biology and Technology. 41(2): 135-142.

Tian S., Xu Y., Jiang A. \& Gong Q. (2002). Physiological and quality responses of longan fruit to high $\mathrm{O}_{2}$ or high $\mathrm{CO}_{2}$ atmospheres in storage. Postharvest Biology and Technology. 24(3): 335-340.

Wang Y., Bai J. \& Long L. E. (2015). Quality and physiological responses of two late-season sweet cherry cultivars 'Lapins' and 'Skeena' to modified atmosphere packaging (MAP) during simulated long distance ocean shipping. Postharvest Biology and Technology. 110: 1-8.

Wang Y. \& Sugar D. (2013). Internal browning disorder and fruit quality in modified atmosphere packaged 'Bartlett' pears during storage and transit. Postharvest Biology and Technology. 83: 72-82. 